\title{
PERCEPÇÃO AMBIENTAL REFERENTE AOS EIXOS DA CARTILHA A3P EM UMA INSTITUIÇÃO PÚBLICA DO MUNICÍPIO DE CAMPO MOURÃO (PR)
}

\author{
Ana Flávia Bilmayer ${ }^{1}$ \\ Larissa Stevanato Borges ${ }^{2}$ \\ Marcia Aparecida de Oliveira ${ }^{3}$
}

Resumo: A preocupação com as questões ambientais vem sendo abordada de diversas formas, especialmente com o passar dos anos por meio de convenções que abordam o tema. No Brasil, o Ministério do Meio Ambiente criou a Agenda Ambiental para a Administração Pública (A3P) que define eixos temáticos com o intuito de avaliar o nível de percepção referente a aspectos gerais sobre meio ambiente. Esse trabalho, baseado nos eixos da Cartilha A3P, objetivou avaliar a percepção ambiental do quadro de membros efetivos e de colaboradores de uma instituição pública do município de Campo Mourão. Com a aplicação de um questionário que contemplou os eixos propostos pela A3P, foi possível evidenciar que a instituição possui algumas práticas de gestão ambiental, podendo ser inseridas outras a partir da sensibilização dos colaboradores.

Palavras-chave: Educação Ambiental, Órgão Público, Eixos Temáticos.

\footnotetext{
1 Universidade Tecnológica Federal do Paraná. E-mail: ana-bilmayer@hotmail.com Universidade Tecnológica Federal do Paraná. E-mail: larissastevanato@gmail.com.

3 Universidade Tecnológica Federal do Paraná. E-mail: moliveira@utfpr.edu.br
}

Revbea, São Paulo, V. 14, № 2: 343-353, 2019.

revista brasileira educação ambiental 


\section{Introdução}

Os diferentes impactos ambientais referem-se ao tipo de relação que o ser humano estabelece com o meio ambiente ao longo de sua evolução enquanto espécie biológica. O homem desenvolveu sua organização social e, junto com ela, criou sua cultura, gerando novas formas de convívio com a natureza (DIAS; LEAL; CARPI JUNIOR, 2016). Esta convivência nem sempre é harmônica, sendo necessário pensar em mecanismos que auxiliem o homem a tomar consciência dos impactos ocasionados ao meio ambiente, em razão da atividade antrópica.

Isto posto, considera-se que a avaliação da percepção é um importante instrumento para a construção e a formação de novos valores e condutas no espaço educacional, uma vez que, por meio da compreensão da percepção ambiental dos agentes sociais envolvidos, é possível avaliar e identificar aspectos relacionados as interações do homem, sociedade e natureza, constituindo-se em um importante campo para pesquisas interdisciplinares (SILVA, 2013).

Rosa e Silva (2002) definem percepção ambiental pela maneira de como os indivíduos veem, compreendem e se comunicam com o ambiente, considerando as influências ideológicas de cada sociedade.

Portanto, a avaliação da percepção ambiental possibilita condicionar os envolvidos à reflexão e conscientização das relações do indivíduo para com o ambiente, contribuindo para a formação de vínculos afetivos positivos, que levam a modificação dos valores ambientais atribuídos pelas pessoas.

Da mesma forma, a partir da percepção ambiental é possível identificar formas precisas para desenvolver ações voltadas à Educação Ambiental (SILVA; 2013), buscando despertar a preocupação individual e coletiva para a questão ambiental, garantindo o acesso à informação em linguagem adequada, contribuindo para o desenvolvimento de consciência crítica e estimulando os enfrentamentos das questões ambientais e sociais (MOUSINHO, 2003).

A Educação Ambiental surge como uma medida técnica e institucional, proposta em nível internacional emergente, voltada para informar o homem a respeito de problemas ambientais, desenvolvendo consciência, comportamentos e ações adequadas ao uso do meio ambiente e à sua proteção (RAMOS, 1996).

Neste pressuposto a preocupação ambiental vem sendo abordada de diversas formas com o passar dos anos. Diversas convenções internacionais trataram o conceito de desenvolvimento sustentável, que passou a ser um referencial nos países do mundo inteiro. Como primeiro pronunciamento oficial sobre a necessidade de Educação Ambiental em escala mundial, foi realizada a Conferência das Nações Unidas sobre o Meio Ambiente Humano, em Estocolmo no ano de 1972. Na ocasião, colocou-se a responsabilidade do ser humano em relação ao ambiente, onde a educação adquire importância singular para a solução de problemas. $O$ intuito principal foi promover 0 intercâmbio de informações, investigação, formação e elaboração de material Revbea, São Paulo, V. 14, № 2: 343-353, 2019. 
educativo, visando a elaboração de estratégias globais para a proteção do meio ambiente e dos recursos naturais (RAMOS, 1996).

Em âmbito nacional, a Política Nacional do Meio Ambiente, instituída a partir da Lei Federal ํo 6.938/1981, determina o início das ações voltadas à conservação ambiental e incorporação do tema nas atividades de diversos setores da sociedade. Dentre esses setores, a administração pública que tem como necessidade, implementar iniciativas relacionadas a ações de desenvolvimento sustentável.

Posteriormente, na Rio 92 foi anunciada a necessidade de criar uma aliança entre todos os povos em prol de uma sociedade sustentável. A consequência desta conferência foi a aprovação de vários documentos como a declaração do Rio de Janeiro, a convenção sobre mudanças climáticas, a declaração de princípios sobre florestas e a Agenda 21, que buscou identificar os problemas prioritários, os recursos e os meios necessários para enfrentálos, além de metas a serem atingidas nas próximas décadas (BEZERRA et al.,2009).

Nesse sentido, o Ministério do Meio Ambiente criou em 2002 a Agenda Ambiental para a Administração Pública (A3P) que tem como intuito buscar a adoção de novos padrões de consumo e produção sustentáveis dentro dos órgãos públicos.

De acordo com a cartilha ambiental, as instituições precisam "dar o exemplo" e fomentar ações que priorizem a política dos 5 R's: Repensar, Reduzir, Reaproveitar, Reciclar e Recusar consumir produtos que gerem impactos socioambientais significativos. A A3P foi estruturada em cinco eixos temáticos prioritários, sendo eles: o uso racional dos recursos naturais e bens públicos, gestão adequada de resíduos gerados, qualidade de vida no ambiente de trabalho, sensibilização e capacitação dos servidores e licitações sustentáveis.

Os eixos foram tomados como referência, para avaliar o nível de percepção referente a aspectos gerais sobre meio ambiente e ainda, aspectos ambientais específicos ao ambiente de trabalho, englobando a geração e segregação de resíduos sólidos, o consumo de água e energia e, a manutenção da frota oficial de veículos.

Nesse sentido, o presente estudo objetivou avaliar a percepção ambiental do quadro de membros efetivos e de colaboradores de uma instituição pública do município de Campo Mourão, tomando como base os eixos contemplados pela Cartilha da Agenda Ambiental na Administração Pública (A3P), a fim de propiciar maior envolvimento e sensibilização dos seus integrantes quanto às questões ambientais. 


\section{Metodologia}

O presente estudo foi realizado em uma instituição pública localizada no município de Campo Mourão - PR, cujo o quadro de funcionários é composto por 03 (três) cargos de chefia, 06 (seis) cargos de assessoria, 01 (um) de auditoria fiscal, 01 (um) de assistência social, 01 (um) de prestador de serviços gerias, 02 (dois) cargos de estagiários de pós-graduação (curso de Direito e outro de Engenharia Ambiental), 17 (dezessete) estagiários de graduação, sendo 14 (quatorze) acadêmicos de Direito e 3 (três) de Engenharia Ambiental, totalizando 31 (trinta e um) membros e colaboradores.

A fim de avaliar a percepção ambiental dos membros e colaboradores da Instituição, aplicou-se um questionário contendo 23(vinte e três) questões objetivas, que teve como base de elaboração os eixos temáticos abordados pela Cartilha A3P. O questionário contemplou questões referentes a aspectos gerais sobre meio ambiente e ainda, aspectos ambientais específicos ao ambiente de trabalho.

A Cartilha A3P segue cinco eixos temáticos sendo eles: uso racional dos recursos naturais e bens públicos, gestão adequada dos resíduos gerados, qualidade de vida no ambiente de trabalho, sensibilização e capacitação dos servidores e licitações sustentáveis. O primeiro eixo abrange uso racional dos recursos naturais podendo ser água, energia etc., implica em usá-los de maneira econômica e racional evitando que ele seja desperdiçado. A gestão adequada dos resíduos é embasada na política dos 5 R's (Repensar, Reduzir, Reutilizar, Reciclar e Recusar) que tem como intuito reduzir o consumo e combater o desperdício dos resíduos sólidos gerados. Para a qualidade de vida no ambiente de trabalho é necessário ações para o desenvolvimento pessoal e profissional, buscando permanentemente a melhoria contínua. $O$ eixo sensibilização e capacitação dos servidores visa concretizar a consciência cidadã dos servidores com responsabilidade socioambiental. Por fim, as licitações sustentáveis devem atentar-se a aquisições de produtos e serviços sustentáveis para a conservação do meio ambiente e melhor custo benefício.

O questionário funciona como uma interessante e facilitadora ferramenta para obtenção de dados, uma vez que, não requer treinamento para elaboração, mantém o anonimato das respostas e as pessoas se sentem mais à vontade para se expor (DRAMBROS, SENNA, ALVES; 2014).

O questionário aplicado neste estudo encontra-se no Apêndice 1.

\section{Resultados e Discussão}

Foram aplicados um total de 31 questionários, obtendo-se 26 questionários respondidos. Com esse resultado, observa-se que a taxa de retorno foi superior a $80 \%$, sendo, portanto, positiva. De acordo com os autores Marconi e Lakatos (2005), em média, 25\% dos questionários expedidos são devolvidos ao pesquisador. Fatores como facilidade de preenchimento, 
formatação das perguntas, extensão e a finalidade do questionário, podem ser considerados influenciadores diretos para retorno dos questionários.

\section{Aspectos gerais sobre meio ambiente}

As poluições, mudanças climáticas, desmatamentos, racionamento de água e energia podem ser sentidos de intensidades diferentes por diferentes pessoas. Quanto a isso, a maioria dos colaboradores e membros da Instituição $(92 \%)$, declararam que as problemáticas ambientais afetam o dia-a-dia em diferentes magnitudes, pois deste montante $60 \%$ afirmam que os problemas ambientais pouco fazem parte do seu dia-a-dia, enquanto $40 \%$ alegam ser atingidos em maior intensidade. Afetando ou não seu dia-a-dia, as questões ambientais foram consideradas problemas de ordem primária na vida dos entrevistados (58\%), evidenciando preocupação com a problemática.

As práticas de gestão ambiental podem ser uma forma simples de demonstrar alguma preocupação com o meio ambiente, pois as pessoas passam a contribuir com pequenas e significativas ações voltadas a economia de água e energia, consumo de produtos orgânicos e ecologicamente sustentáveis ou ainda a contribuição em práticas de coleta seletiva, entre outras ações. O conhecimento de algum tipo de prática de gestão ambiental foi unânime dentre os avaliados, destacando a coleta seletiva e a economia de energia e água, como as práticas mais recorrentes (Figura 1).

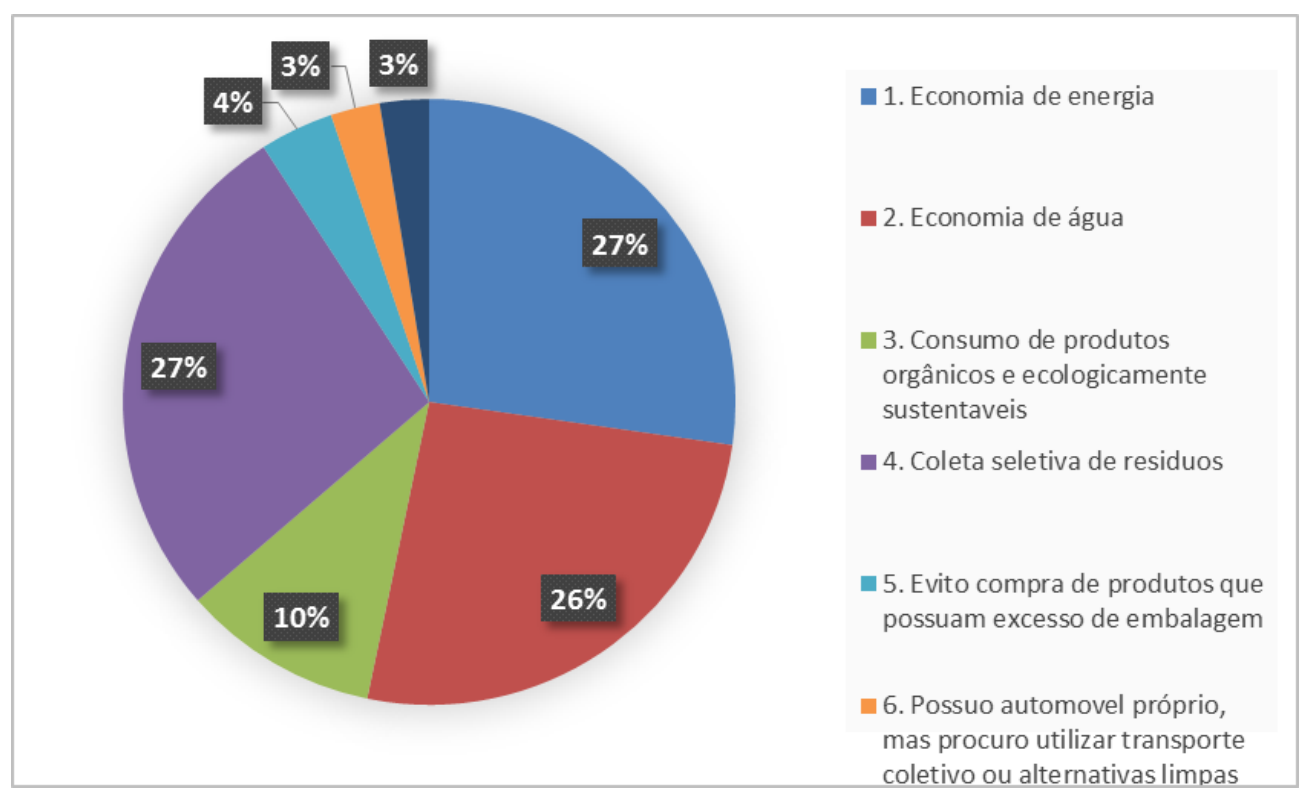

Figura 1: Práticas de gestão ambiental desenvolvidas pelos colaboradores e membros da Instituição. Fonte: Autoria própria

A diminuição do uso dos recursos naturais e geração de resíduos atinge não somente a área ambiental, mas também a economia, por meio da minimização de gastos com produtos (STEPHANOU, 2009) 
Com o levantamento de informações referente ao conhecimento das práticas ambientais realizadas pelos avaliados, tornou-se necessário aferir temas pontuais que interferem direta e indiretamente o meio ambiente, no ambiente de trabalho.

\section{Meio Ambiente e ambiente de trabalho}

\section{Segregação de resíduos}

Uma das principais práticas de gestão ambiental executadas pelos membros e colaboradores da Instituição é a Coleta Seletiva, no entanto, verificou-se que $62 \%$ dos funcionários nunca receberam capacitação referente a segregação de resíduos, no ambiente de trabalho. Essa informação corrobora ao entendimento de que os funcionários estejam desinformados, realizando a separação de forma errônea ou ineficiente. Embora não tenha ocorrido uma capacitação presencial voltada à segregação de resíduos, $77 \%$ dos analisados já notaram algum tipo de material destinado a conscientização e instrução para a segregação de resíduos em ambiente de trabalho, mais especificamente, na cozinha.

Com a aplicação do questionário foi possível identificar que $88 \%$ dos respondentes possuem em sua sala duas lixeiras para a separação de resíduos, rotuladas como material orgânico e reciclável. Entretanto, mesmo havendo lixeiras, 19\% não costumam segregar esses resíduos. Nos ambientes onde não há lixeiras (12\%), 02 colaboradores costumam segregar os resíduos, destinando-o a lixeira mais próxima, e 01 não o faz.

No que se refere a produção de resíduos em ambiente de trabalho, listou-se, principalmente, o consumo de copos descartáveis e folhas destinadas a impressão de documentos. Observou-se que $23 \%$ declararam utilizar copo plástico descartável, ainda que existam à disposição copos e canecas reutilizáveis. Uma alternativa para redução deste índice pode ser o desenvolvimento de atividades de sensibilização, direcionando a utilização de copos com maior vida útil, como o vidro ou plásticos duráveis. Quanto à utilização de papel, constatou-se que são disponibilizados à Instituição apenas folhas de papel reciclado, vantagem ambiental frente à utilização de folhas brancas, que para serem usadas faz-se necessário a solicitação perante a Coordenação Administrativa, exigindo certa burocracia e demandando tempo.

A prática de utilizar a folha de papel reciclado implica na redução do resíduo, evitando o desperdício de recursos naturais e gerando economia financeira para sua produção. Além disso, com a produção de papel reciclado minimiza-se a utilização de componentes químicos, requeridos no processo de branqueamento, reduzindo a poluição ambiental (ROSA et al., 2005)

Ainda, como o volume de papel produzido pela Instituição é significativo, foi questionado qual procedimento é adotado ao se descartar uma folha na lixeira, constatando-se que $41 \%$ amassam as folhas, jogando-as na lixeira, fato que não é recomendável (Figura 2), pois de acordo com o Ministério do Meio Ambiente (2009), é fundamental que o papel não seja amassado, nem Revbea, São Paulo, V. 14, № 2: 343-353, 2019. 
misturado com outros tipos de materiais para que não reduza seu valor no momento da reciclagem.

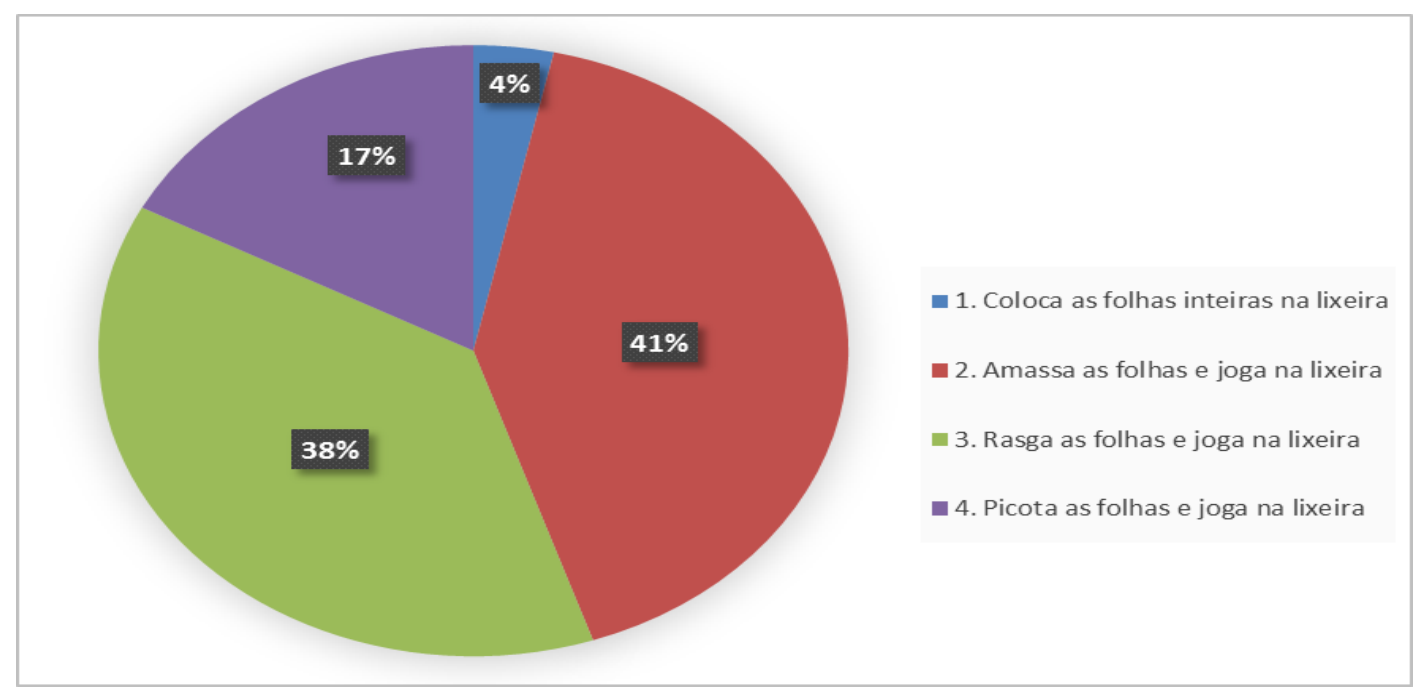

Figura 2: Procedimentos adotados quanto ao descarte de papel. Fonte: Autoria própria

Por fim, ao se questionar sobre a utilização de ambos os lados da folha para impressão e/ou rascunho, $50 \%$ dos respondentes afirmaram não utilizar o verso, representando assim a geração de um resíduo que poderia ser evitada ou minimizada, através do desenvolvimento de ações de Educação Ambiental.

\section{Economia de recursos: Água e Energia}

Atualmente, as políticas direcionadas a economia de água se fazem presentes em ambientes públicos e privados. A adoção de práticas como substituição de torneiras e caixas de descarga por dispositivos mais econômicos resultam na redução de vazão de água requerida, minimizando o consumo deste recurso tido como fundamental (A3P, 2009). Do total de entrevistados, $58 \%$ afirmaram que os banheiros utilizados em seu ambiente de trabalho não possuem válvulas de descarga com regulagem de água. Quanto as torneiras dos banheiros, cozinha e lavanderia, verificou-se que $53 \%$ dos respondentes identificaram algum tipo de vazamento ou desregulagem nas mesmas, deste montante, $17 \%$ afirmaram que foram efetuadas manutenções nos equipamentos que apresentaram problema.

A conscientização referente ao uso da água, constitui-se como uma importante ferramenta para redução de seu desperdício. Sobre esse quesito, $81 \%$ dos entrevistados declararam a inexistência de materiais relacionados a economia de água, evidenciando que essa problemática pode ser melhor explorada no ambiente de estudo.

No que se refere ao consumo de energia, $88 \%$ dos respondentes afirmaram que utilizam em seu ambiente de trabalho lâmpadas fluorescentes comuns e $12 \%$ usam a fluorescente econômica. As lâmpadas fluorescentes 
iluminam de forma otimizada, são mais econômicas quando comparadas às demais, possuem excelente prazo de vida útil, além disso, esse tipo de iluminação reduz a emissão de dióxido de carbono $\left(\mathrm{CO}_{2}\right)$, cujo impactos ambientais já são muito conhecidos e discutidos por pesquisadores da área ambiental.

Constatou-se que $100 \%$ dos colaboradores revelaram efetuar o desligamento de luzes ao fim do expediente ou quando se ausentam da sala por mais de uma hora. Por outro lado, $23 \%$ assumiram que não desligam os aparelhos eletrônicos nas mesmas condições, implicando em consumo de energia desnecessário. Quanto ao sistema de refrigeração dos ambientes de trabalho, verificou-se que $30 \%$ (8 colaboradores) não possuem ar condicionado em suas salas, enquanto os que possuem, percebe-se que o uso é feito de forma consciente, optando por utilizá-lo somente em dias quentes, mantendo portas e janelas fechadas.

A Cartilha A3P (2009), dá orientações no que diz respeito à eficiência energética em órgãos públicos, dentre elas: priorizar à iluminação natural, abrindo janelas, cortinas e persianas; apagar as luzes de ambientes vazios ou quando for ausentar-se; não deixar equipamentos elétricos ligados por muito tempo sem uso. Observa-se que referidas ações foram desempenhas, em maior ou menor escala, na instituição.

\section{Manutenção da frota oficial}

De acordo com a Cartilha A3P (2009), as revisões preventivas e periódicas sugeridas pelos fabricantes e o uso de combustível recomendado, são itens necessários para manutenção adequada de veículos, contribuindo para o prolongamento de sua vida útil. Com a aplicação do questionário, constatou-se que todos os colaboradores (7) que utilizam o veículo oficial, afirmaram que a manutenção do mesmo é feita conforme necessidade e que ações preventivas são feitas anualmente, além disso, o abastecimento do veículo é feito de acordo com o recomendado pelo fabricante, aspecto que contribuí para aumento da vida útil do bem e proporciona menor impacto ambiental, no que se refere ao lançamento de poluentes atmosféricos.

\section{Considerações finais}

A responsabilidade de práticas de gestão ambiental é essencial no ambiente de interação social dos indivíduos. Em órgãos públicos esse quesito precisa ser estendido com o intuito de abranger a todos os envolvidos.

No estudo realizado, foi possível evidenciar que há falta de uniformidade na prática de gestão ambiental na instituição pública avaliada. Enquanto alguns colaboradores declararam segregar os resíduos orgânicos dos recicláveis, outros não realizam esse procedimento, mesmo possuindo lixeiras de segregação nos setores. Além disso, verificou-se que todos os entrevistados conhecem alguma prática de gestão ambiental e realizam alguma 
em sua casa, destacando-se a coleta seletiva e a economia de energia e água, como as práticas mais recorrentes.

No que diz respeito à economia de água, $81 \%$ dos entrevistados declararam a inexistência de materiais relacionados à economia desse quesito, evidenciando que essa problemática pode ser explorada no ambiente de estudo. Quanto a economia de energia, todos os colaboradores declararam efetuar o desligamento das lâmpadas ao se ausentar das salas, porém, alguns não desligam os equipamentos eletrônicos, fator esse que pode ser readequado para a economia desse recurso.

Para a manutenção da frota oficial, constatou-se que aqueles que utilizam os veículos realizam o reparo necessário para o bom funcionamento dele, evitando, assim, o desgaste do veículo e contaminação do ambiente.

De maneira geral, constatou-se que a instituição possui algumas práticas de gestão ambiental, podendo ser inserido algumas com a conscientização dos funcionários. Atuando dessa forma, os órgãos públicos dariam exemplo para a sociedade possuindo maior credibilidade para cobrar atitudes ecologicamente corretas dos cidadãos.

\section{Referências}

BEZERRA, A. S. et al. A evolução histórica da questão ambiental. Anais do $25^{\circ}$ Congresso Brasileiro de Engenharia Sanitária e Ambiental. Recife, PE. 2009.

DIAS, L. S., LEAL, A.C. CARPI JUNIOR, S. Educação Ambiental: conceitos, metodologia e práticas. Tupã: ANAP, 2016.

RAMOS, E.C. Educação Ambiental: evolução histórica, implicações teóricas e sociais. Uma avaliação crítica. Curitiba, 1996. Dissertação (Mestrado em Educação)-Setor de Educação, Universidade Federal do Paraná.

ROSA, L. G.; SILVA, M. M. P. Percepção ambiental de educandos de uma escola do ensino fundamental. In: Anais. VI Simpósio Ítalo Brasileiro de Engenharia Sanitária e Ambiental. Vitória (ES), Brasil. Vitória, 2002.

MOUSINHO, P.; TRIGUEIRO, A. Meio ambiente no século 21. Rio de Janeiro: Sextante, 2003

MARCONI, M. A.; LAKATOS, E. M. Fundamentos de metodologia científica. 6ª Ed. São Paulo: Atlas, 2005.

ROSA, B. N. et al. A importância da reciclagem do papel na melhoria da qualidade do meio ambiente. XXV Encontro Nac. de Eng. de Produção-Porto Alegre, RS, Brasil, 2005.

STEPHANOU, J. J. Gestão de resíduos sólidos: um modelo integrado que gera benefícios econômicos, sociais e ambientais. Trabalho de Conclusão de Curso de Especialização da Universidade Federal do Rio Grande do Sul. 2009. 


\section{Apêndice - Questionário: Educação Ambiental Com Base A3p}

\section{Aspectos gerais sobre Meio Ambiente}

1) As questões ambientais, como poluição, desmatamentos, racionamento de água e/ou energia, etc. afetam seu dia-a-dia?

( ) Sim, um pouco ( ) Sim, bastante ( ) Não afetam

2) Afetando ou não ou seu dia-a-dia, as questões ambientais (listadas anteriormente) fazem parte das suas preocupações?

( ) Sim, me preocupo muito ( ) Sim, mas é uma preocupação secundária

Não me preocupo

3) Você conhece alguma prática de gestão ambiental?

( ) $\operatorname{Sim}($ ) Não

4) Você realiza alguma prática de gestão ambiental na sua casa?

( ) $\operatorname{Sim}$ ( ) Não

Em caso afirmativo, quais dessas práticas são as mais executadas:

( ) Economia de energia

( ) Economia de água

( ) Consumo de produtos orgânicos e ecologicamente sustentáveis

( ) Coleta Seletiva de Resíduos

( ) Evito compra de produtos que possuem excesso de embalagem

( ) Possuo automóvel próprio, mas procuro utilizar transporte coletivo ou alternativas limpas

( ) Outro, especifique

\section{Meio Ambiente e ambiente de trabalho}

5) Você já passou por alguma capacitação referente a segregação de resíduos?
( ) Sim
( ) Não

6) Há algum material de conscientização referente a segregação de resíduos no seu ambiente de trabalho? (Panfletos, cartazes, etc.)

( ) Sim ( ) Não

7) Em seu ambiente de trabalho há lixeiras para separação de resíduos?

( ) Sim ( ) Não

8) Você costuma separar resíduos orgânicos dos recicláveis?

( ) Sim ( ) Não

9) Você costuma utilizar copos descartáveis para tomar água, café ou chá?

( ) Sim ( ) Não

10) Em seu ambiente de trabalho, qual o tipo de papel utilizado normalmente?

( ) Folha branca ( ) Folha de papel reciclável

11) Você costuma utilizar os dois lados das folhas para a impressão ou anotações?

( ) $\operatorname{Sim}$ ( ) Não

12) Ao jogar papéis no lixo, você costuma fazer quais destes procedimentos:

( ) Coloca as folhas inteiras na lixeira

( ) Amassa as folhas e joga na lixeira

( ) Rasga as folhas e joga na lixeira

( ) Picota as folhas e joga na lixeira

Revbea, São Paulo, V. 14, № 2: 343-353, 2019. 
13) Nos banheiros do seu ambiente de trabalho, há válvulas de descarga com regulagem de água?

( ) Sim

( ) Não

14) Nas torneiras do seu ambiente de trabalho, foi identificado algum tipo de vazamento ou desregularem?

( ) Sim ( ) Não

Em caso afirmativo, foi realizado readequação:

( ) Sim

( ) Não

( ) Desconheço

15) Em seu ambiente de trabalho, há algum material de conscientização referente a economia de água?

( ) Sim ( ) Não

16) Em sua sala, qual o tipo de lâmpadas utilizadas?

( ) Fluorescentes comuns ( ) Fluorescentes econômicas Incandescentes

17) Você costuma desligar as luzes de sua sala ao se afastar por mais de uma hora ou ao sair do trabalho ao final do expediente?

( ) Sim ( ) Não

18) Você costuma desligar os aparelhos eletrônicos de sua sala ao se afastar por mais de uma hora ou ao sair do trabalho ao final do expediente?

( ) Sim ( ) Não

19) Na sua sala, há ar condicionado?

( ) Sim ( ) Não

Em caso afirmativo, quais práticas são executadas:

( ) Utiliza-se somente em dias quentes

( ) Em dias frescos, opta-se por manter portas e janelas abertas

( ) Utiliza-se sempre

( ) Quando utilizado, opta-se por fechar portas e janelas.

20) Quanto ao veículo disponível para utilização, é realizada manutenção conforme necessidade?

( ) Sim ( ) Não ( ) Desconheço

21) Qual o tipo de combustível utilizado no abastecimento do veículo?

( ) Etanol ( ) Gasolina ( ) Gasolina Aditivada ( ) Flex ( ) Diesel ( ) Desconheço 